\title{
Gastric and gall bladder emptying of a mixed meal are not coordinated in liver cirrhosis - a simultaneous sonographic study
}

\author{
M Acalovschi, D L Dumitraşcu, I Csakany
}

\begin{abstract}
Background and aim-An impaired contractility has been suggested as a contributor to the increased incidence of gallstones in liver cirrhosis, but the few studies on gall bladder emptying in cirrhotics offered contradictory results. Ingestion of a meal triggers the physiological pathway of gall bladder emptying; therefore, it was decided to analyse postprandial kinetics by investigating simultaneously the rates of gastric and gall bladder emptying of a mixed meal in patients with liver cirrhosis.
\end{abstract}

Methods-Gastric and gall bladder emptying were measured using ultrasound techniques after a solid-liquid meal (14 $\mathrm{g}$ fat, $425 \mathrm{kcal}$ ) in 24 patients with liver cirrhosis and in 12 controls. None of the subjects had gall bladder disease. Sequential changes in cross sectional area of the gastric antrum and in gall bladder volume were represented as a monoexponential process after the test meal. Cirrhotic patients were analysed according to the severity of disease (Child classes). The presence of portal gastropathy was assessed by endoscopy. Differences between groups were assessed using the two tailed Student's $t$ test for unpaired observations and the correlations by linear regression (Pearson's coefficient).

Results-It was found that gastric emptying after the solid-liquid meal was delayed in cirrhotic patients compared with controls. Gall bladder emptying was significantly diminished in cirrhotic patients: the area under curve was greater in Child A ( $=0.01)$, Child B $(p=0 \cdot 04)$, and Child C ( $p=0.014)$ cirrhotics compared with controls. No correlation was found between the variables of gastric and gall bladder emptying. Gall bladder refilling began earlier in cirrhotics than in controls, before completion of gastric emptying.

Conclusions-These results indicate the lack of coordination between gastric and gall bladder emptying in liver cirrhosis. They also support the hypothesis that diminished gall bladder contractility might contribute to the increased gallstone formation in liver cirrhosis.

(Gut 1997; 40: 412-417)

Keywords: gastric emptying, gall bladder emptying, ultrasonography, liver cirrhosis.
Liver cirrhosis is associated with a high prevalence of gallstones, as a result of $\vec{\circ}$ hypersplenism and alterations in hepatic metabolism. Impaired gall bladder motility has $\vec{\omega}$ also been suggested as a contributor to this $\stackrel{\circ}{\varrho}$ increased incidence of gallstones, but the few studies on gall bladder emptying in cirrhotics $\overrightarrow{0}$ offered contradictory results. ${ }^{1-5} \quad \dot{\omega}$

Postprandial gall bladder emptying is mainly coordinated by the rate of gastric emptying of food into the duodenum, with subsequent cholecystokinin (CCK) release. ${ }^{67}$ An accel- $\vec{z}$ erated gastric emptying in portal hypertension, found in some studies, has been attributed to $\stackrel{\rho}{J}$ a decreased compliance and/or altered motility $\overrightarrow{0}$ of the gastric antrum. ${ }^{8-12}$ Wegener et al did not $\vartheta$ find significant changes in gastric emptying and $\square$ whole gut transit in alcoholic cirrhotics when compared with controls. ${ }^{13}$ Isobe et al, on the contrary, have shown that gastric emptying half time was significantly higher in patients with $\stackrel{\circ}{\mathbb{D}}$ liver cirrhosis than in controls ${ }^{14}$ and recently, $\stackrel{2}{\overrightarrow{2}}$ delayed gastric emptying was described in $\frac{0}{3}$ cirrhotic patients with antral vascular ectasia. ${ }^{15}$

We undertook the present investigation in order to find out whether gall bladder emptying was impaired in liver cirrhosis and to analyse the temporal and quantitative relation $\frac{5}{3}$ between gastric and gall bladder emtpying in this disease. Sonography is increasingly used $\frac{0}{3}$ for the estimation of gastric emptying and is the "gold standard" for the study of gall bladder motility. We carried out real time ultra- $\frac{D}{0}$ sonography for the simultaneous measurement of gastric and gall bladder emptying.

\section{Subjects}

We studied 24 patients with liver cirrhosis admitted to our clinic and 12 controls, hospitalised patients without liver diseases. ? Subjects cholecystectomised or having gall bladder diseases were not included in the $\frac{\vec{P}}{\vec{D}}$ study. None had undergone prior gastric or $\stackrel{\square}{\overparen{P}}$ ileal surgery and none was overtly diabetic.

The diagnosis of liver cirrhosis was made by histological and/or laparoscopic examination in 8 15 patients. In the other patients, in whom biopsy was contraindicated or refused, liver cirrhosis was diagnosed on the basis of clinical, $\stackrel{?}{?}$ biochemical, ultrasonographic features, and/or presence of oesophageal varices. The size of varices was assigned as described by Raws $e t$ $a l .{ }^{16}$ Aetiology of cirrhosis was established by history of alcohol intake, presence of HBsAg or anti-HCV antibodies and the liver histology. Cirrhotics were allocated to Child classes using 
TABLE I Characteristics of patients included in the study

\begin{tabular}{|c|c|c|c|c|}
\hline & \multirow[b]{2}{*}{ Controls } & \multicolumn{3}{|c|}{ Liver cirrhosis } \\
\hline & & Child $A$ & Child B & Child C \\
\hline No of patients: & 12 & 8 & 8 & 8 \\
\hline Male & 7 & 5 & 7 & 4 \\
\hline Female & & 3 & 1 & 4 \\
\hline Age (mean (SD)) (years) & $50 \cdot 7(8 \cdot 2)$ & $46.9(10 \cdot 3)$ & $45 \cdot 6(7 \cdot 2)$ & $51.9(6.9)$ \\
\hline \multicolumn{5}{|l|}{ Aetiology of cirrhosis: } \\
\hline Viral & & 2 & 1 & 1 \\
\hline Alcoholic & & 2 & 4 & 3 \\
\hline Viral+alcoholic & & 3 & 1 & 2 \\
\hline Cryptogenic & & 1 & 2 & 2 \\
\hline \multicolumn{5}{|l|}{ Oesophageal varices: } \\
\hline Absent & & 1 & 1 & 1 \\
\hline 1st degree & & 3 & 1 & - \\
\hline 2nd degree & & 2 & 6 & 5 \\
\hline 3rd degree & & 2 & - & 2 \\
\hline \multicolumn{5}{|l|}{ Gastroduodenal lesions: } \\
\hline Portal gastropathy & & - & - & 2 \\
\hline Duodenal ulcer & - & - & - & 1 \\
\hline Gastric ulcer & - & - & - & 1 \\
\hline
\end{tabular}

clinical and biochemical factors (eight patients in each class). The characteristics of the patients included in the study are shown in Table I.

Informed consent was obtained from each subject before examination.

\section{Method}

Gastric and gall bladder emtpying were assessed by ultrasound monitoring. All measurements were undertaken by the same operator (DLD).

Gastric emptying was evaluated according to the method of Bolondi et $a l,{ }^{17}$ based on the measurement of antral area in a sagittal section inside the gastric wall through the aorticmesenteric vein plane.

The gall bladder was scanned to visualise its longest axis, width, and depth. Gall bladder volume was calculated using the ellipsoid formula. ${ }^{18}$

The study began at $10 \mathrm{am}$. The subjects fasted for at least 12 hours before the study. None took any medication 24 hours before the study which might have influenced gastrointestinal motility, and none smoked on the morning of the investigation. Patients were instructed to assume the upright position between measuring periods.

After measuring the basal antral area and gall bladder volume, each subject was requested to consume a mixed (solid-liquid meal) consisting of one slice of bread ( $30 \mathrm{~g}$ ), $10 \mathrm{~g}$ butter, one boiled egg, $300 \mathrm{ml}$ tea with $25 \mathrm{~g}$ sucrose. This was equivalent to $14 \mathrm{~g}$ fat and $465 \mathrm{kcal}$. The test meal was finished within 3 or 4 minutes.

The following variables for gastric emptying were evaluated immediately (time 0 ) and every 15 minutes until 90 minutes after the test meal: antral distension (percentage of antral area increase after finishing the meal), minimal postprandial area, and the area under the emptying curve $\left(\mathrm{AUC}_{\mathrm{ST}}\right.$-percentage of basal area at 90 minutes). ${ }^{19}$ The half time (T/2) of gastric emptying was calculated from the linear part of the emptying curve (usually between time 0 and 60 minutes).

Gall bladder function was assessed by analysing at 15 minute intervals (until 90 minutes) after the test meal the following variables: fasting gall bladder volume (FV), minimal residual volume ( $\mathrm{RV}$-smallest volume after the test meal), gall bladder ejection fraction $(\mathrm{FV}-\mathrm{RV} / \mathrm{FV} \times 100)$ and the area under emptying curve $\left(A \mathrm{AC}_{\mathrm{GB}}\right.$-proportional to the degree of gastric emptying during 90 minutes and expressed as percentage of FV). The half contraction time of the gall bladder $(T / 2)$ was calculated in all patients during the time period in which the values were linear with time (usually between 0 and 45 minutes).

\section{Analysis}

Antral areas and gall bladder volumes were expressed as absolute values $\left(\mathrm{cm}^{2}\right.$ or $\left.\mathrm{cm}^{3}\right)$ and as percentage of the respective values at 0 minutes $(100 \%)$.

Data were expressed as mean (SD).

Differences between groups were analysed using the two tailed Student's $t$ test for unpaired observations, with statistical significance set at the $\mathrm{p}<0.05$ level. Correlations were evaluated by linear regression (Pearson's correlation coefficient).

\section{Results}

The aetiology of liver cirrhosis was alcoholic in nine patients $(37 \cdot 5 \%)$, viral in four $(16 \cdot 6 \%)$, mixed-alcoholic and viral B or C in six (25\%), and cryptogenic in five $(20.8 \%)$. The fibre endoscopy revealed portal hypertensive gastrophy in two of the Child C class patients, and a linear or cicatriceal gastric and duodenal ulcer in another two Child C class patients (Table I). Endoscopy was normal in the remaining liver cirrhosis patients and in controls.

We found a strong inverse correlation between antral postprandial distension and $\mathrm{AUC}_{\mathrm{ST}}$ both in controls $(r=-0.747, \mathrm{p}=0.005)$ and in cirrhotics $(r=-0.738, p=0.036)$. The postprandial antral distension was nonsignificantly decreased in Child B and C class patients compared with controls $(p=0 \cdot 075)$. The $\mathrm{AUC}_{\mathrm{ST}}$ was greater in Child $\mathrm{B}$ and $\mathrm{C}$ patients (significantly for Child B patients) than in controls (Table II), indicating impaired gastric emptying. The $T / 2$ of the stomach was similar in controls and cirrhotic patients and did not correlate with the degree of portal hypertension (indicated by the size of oesophageal varices) (Table III).

Fasting gall bladder volume was larger in Child class $C$ cirrhotics $\left(47.5(25) \mathrm{cm}^{3}\right)$ than in controls $\left(27.4(16 \cdot 7) \mathrm{cm}^{3}\right)(\mathrm{p}=0.041)$, but for class $A$ or $B$ patients the difference

TABLE II Variables of gastric emptying of the mixed test meal in cirrhotics (Child class $A, B$ and $C$ ) and controls (means (SD))

\begin{tabular}{llll}
\hline & $\begin{array}{l}\text { Antral } \\
\text { postprandial } \\
\text { distension (\%) }\end{array}$ & $\begin{array}{l}\text { Gastric T/2 } \\
(\text { min) }\end{array}$ & $\begin{array}{l}\text { AUC } \\
\text { antral area } \\
\text { at 90 min) }\end{array}$ \\
\hline Controls & $323 \cdot 3(113 \cdot 9)$ & $18 \cdot 6(9 \cdot 7)$ & $52 \cdot 6(7 \cdot 8)$ \\
Cirrhosis A & $325 \cdot 0(100 \cdot 7)$ & $18 \cdot 4(10 \cdot 9)$ & $59 \cdot 5(15 \cdot 5)$ \\
Cirrhosis B & $286 \cdot 1(91 \cdot 4)$ & $23 \cdot 3(11 \cdot 9)$ & $62 \cdot 7(8 \cdot 5)^{\star}$ \\
Cirrhosis C & $238 \cdot 7(66 \cdot 4)$ & $17 \cdot 2(10 \cdot 9)$ & $61 \cdot 3(14 \cdot 3)$ \\
\hline
\end{tabular}

${ }^{\star} \mathrm{p}=0.013$ 
TABLE III Relation between size of varices and half

NS=non-significant.

TABLE IV Variables of gall bladder motor function after a mixed test meal in cirrhotics and controls (mean (SD))

\begin{tabular}{|c|c|c|c|c|c|}
\hline & $F V(m l)$ & $R V(m l)$ & $E F(\%)$ & $T / 2(\min )$ & $\begin{array}{l}A U C \\
(\% \text { FV } 90 \mathrm{~min})\end{array}$ \\
\hline $\begin{array}{l}\text { Controls } \\
\text { Cirrhosis A } \\
\text { Cirrhosis B } \\
\text { Cirrhosis C }\end{array}$ & $\begin{array}{l}27 \cdot 5(16 \cdot 7) \\
30.7(13.9) \\
31.8(9 \cdot 3) \\
47.6(25 \cdot 0)^{\star}\end{array}$ & $\begin{array}{l}11 \cdot 2(7 \cdot 4) \\
20 \cdot 1(13 \cdot 6) \\
13 \cdot 1(6 \cdot 7) \\
22 \cdot 3(14 \cdot 6)^{\star}\end{array}$ & $\begin{array}{l}70.3(14.8) \\
48.5(14 \cdot 1)^{\star} \\
56.4(15 \cdot 7)^{\star} \\
49.5(9 \cdot 3)^{\star}\end{array}$ & $\begin{array}{l}15 \cdot 8(5 \cdot 9) \\
19 \cdot 9(5 \cdot 3) \\
20 \cdot 9(11 \cdot 8) \\
22 \cdot 1(11 \cdot 3)\end{array}$ & $\begin{array}{l}48 \cdot 4(14 \cdot 0) \\
65 \cdot 3(13 \cdot 0)^{\star} \\
61 \cdot 3(10 \cdot 5)^{\star} \\
64 \cdot 7(11 \cdot 6)^{\star}\end{array}$ \\
\hline
\end{tabular}

${ }^{\star} \mathrm{p}<0.05$ versus controls. emptying time (T/2) of the stomach

\begin{tabular}{lll}
\hline $\begin{array}{l}\text { Oesophageal } \\
\text { varices } \\
\text { (degree) }\end{array}$ & $\begin{array}{l}\text { T/2 of the stomach } \\
\text { (min) } \\
(\text { mean }(S D))\end{array}$ & $p$ Value \\
\hline absent & $20 \cdot 7(12 \cdot 4)$ & NS \\
1 & $22 \cdot 9(6 \cdot 5)$ & NS \\
2 & $18 \cdot 4(10 \cdot 6)$ & NS \\
3 & $16 \cdot 2(11 \cdot 3)$ & NS \\
4 & $20 \cdot 5(10 \cdot 2)$ & \\
\hline
\end{tabular}

bladder emptying. The gall bladder ejection fraction was also significantly reduced in cirrhotics (Table IV).

We found no correlation between $T / 2$ of the gall bladder and age, FV or ejection fraction in controls and liver cirrhosis patients. We noted a strong inverse correlation between gall bladder ejection fraction and $A U C_{G B}$ in liver cirrhosis patients in Child $A, B$, and $C$ class $(r=-0.925,-0.910$ and $-0.890 ; \mathrm{p}=0.001)$ and in controls $(r=-0 \cdot 859, \mathrm{p}=0.0008)$.

The sequential changes in antral area and gall bladder volume could be represented as a monoexponential process after the test meal in between time 0 and 60 (or 45) minutes (Figs 1-4). The gastric and gall bladder emptying curves run almost parallel towards the minimal volumes, splitting during the gall bladder refilling phase. Nevertheless, we found no correlation between variables of gastric and $\overrightarrow{0}$ gall bladder emptying: gastric and gall $\omega$ bladder $\mathrm{T} / 2(\mathrm{p}=0.8)$ or $\mathrm{AUC}_{\mathrm{GB}}$ and $\mathrm{AUC}_{\mathrm{ST}}$ $(p=0.3)$ in cirrhotic patients. The gastric emptying curves indicated a delayed emptying in liver cirrhosis patients but reaching similar magnitude at 90 minutes (about $60 \%$ emptying) as in controls. Gall bladder emptying curves showed a slower emptying with a reduced magnitude in all cirrhotics versus controls.

\section{Discussion}

Gastric emptying is an important physiological motor function of the stomach, as the gastric emptying rate determines the rate at which nutrients are delivered to and assimilated by the small intestine. Gastric meal emptying induces postprandial cholecystokinin release

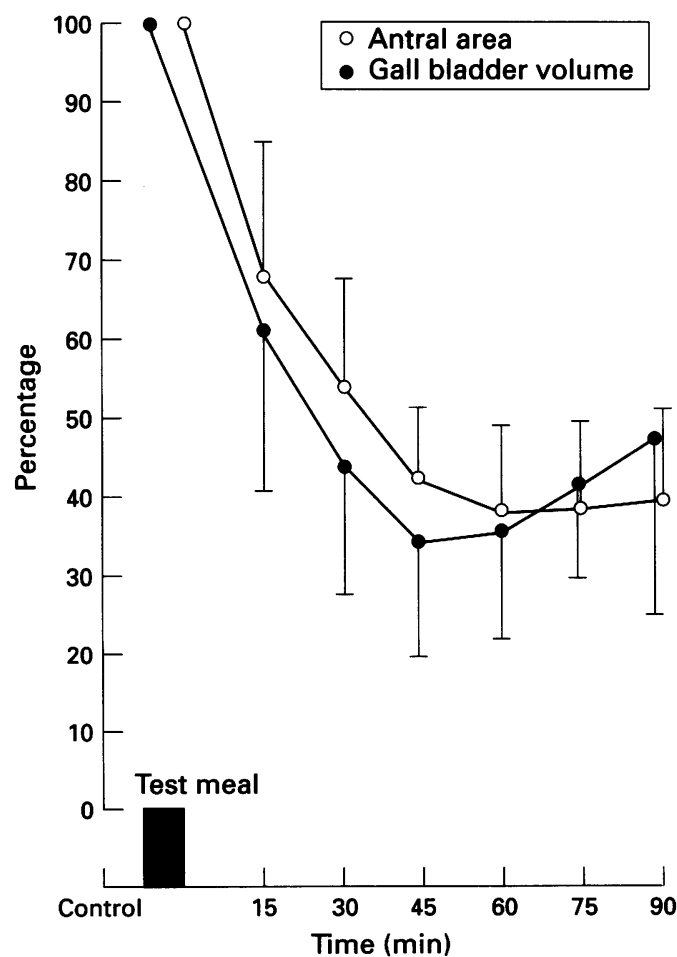

Figure 1: Mean emptying curves of the stomach and the gall bladder determined by sonography in controls. Data are plotted as mean percentage of the residual antral cross sectional area and residual gall bladder volume (expressed as percentage of the respective values at 0 minutes, $100 \%)$. Bars $=S D$.

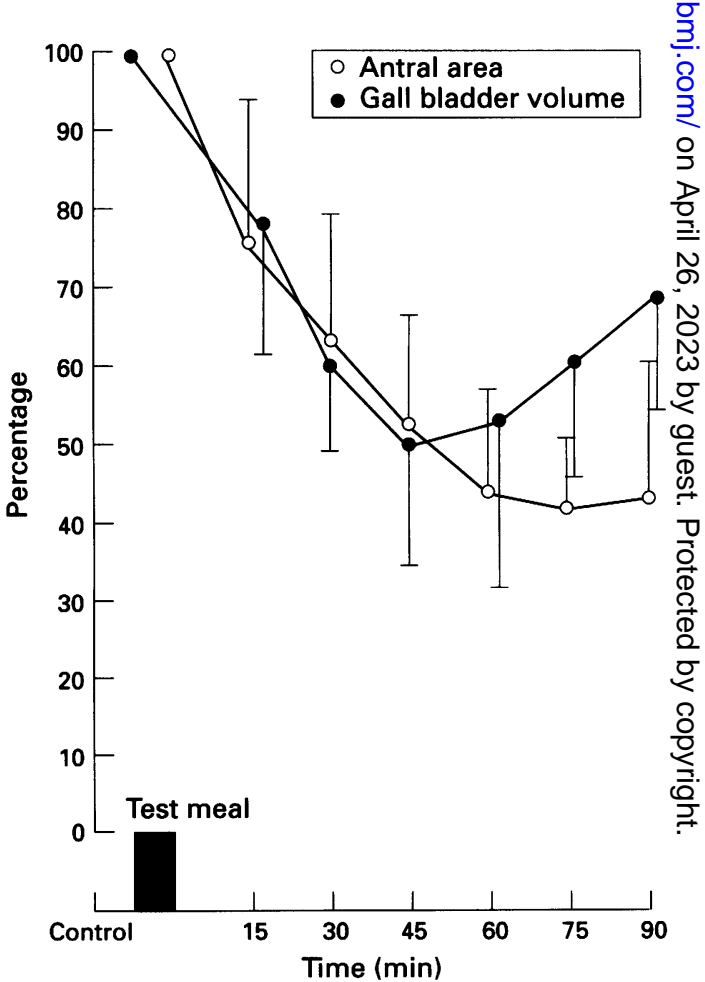

Figure 2: Emptying curves of the stomach and the gall bladder determined by sonography in patients with Child class $A$ liver cirrhosis (mean (SD)). 


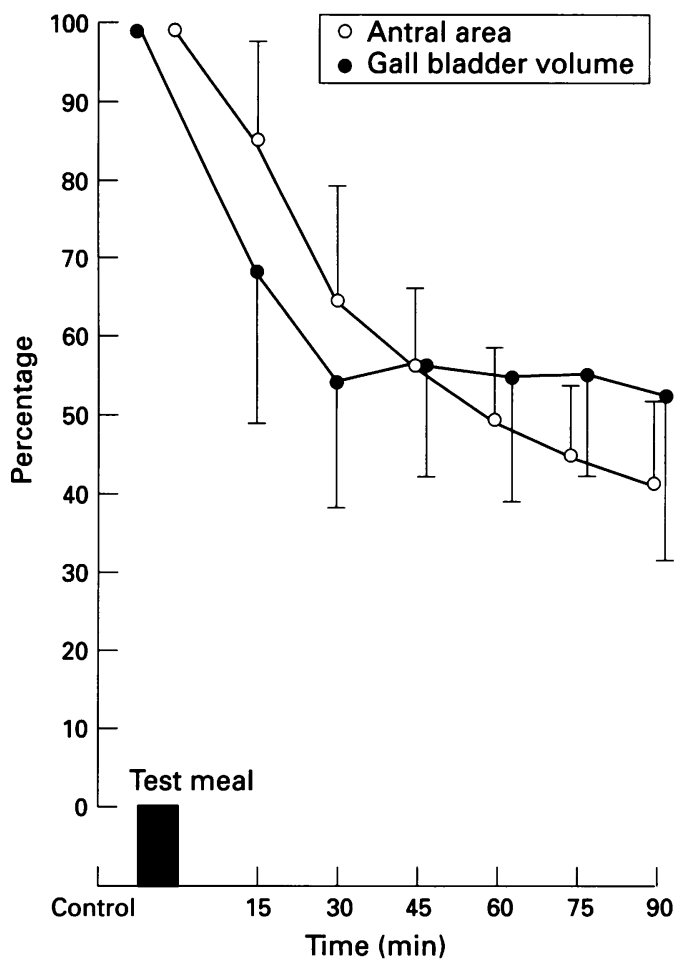

Figure 3: Emptying curves of the stomach and gall bladder determined by sonography in patients with Child class $B$ liver cirrhosis (mean (SD)).

and gall bladder contraction. It has been shown that the rate at which food enters the proximal duodenum modifies the gall bladder emptying rate without affecting the amount of contraction, which seems instead to be more closely related to the calorie/fat content of the meal. ${ }^{70-22}$ The two (fast and slow) phases of gall bladder emptying are followed by gall

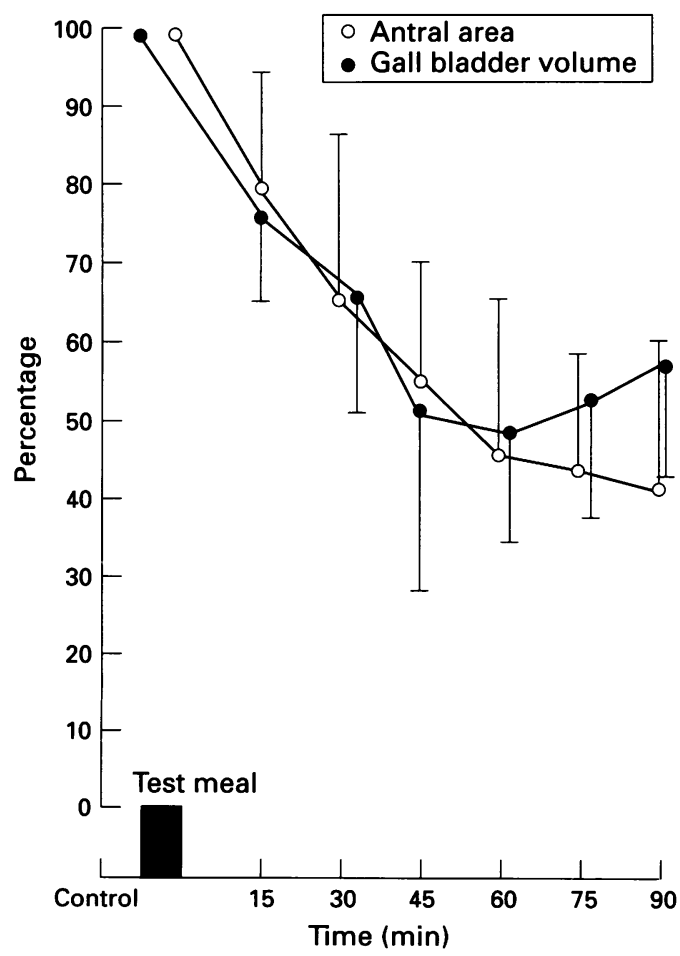

Figure 4: Emptying curves of the stomach and gall bladder determined by sonography in patients with Child class $C$ liver cirrhosis (mean (SD)). bladder refilling; this usually beginning when gastric emptying is completed. ${ }^{6}$

We used a mixed meal to evaluate both gastric and gall bladder emptying. This solidliquid meal containing $14 \mathrm{~g}$ fat has already been shown to cause a significant decrease in normal gall bladder volume ${ }^{2022}$ : for liquid meals, $10 \mathrm{~g}$ fat was found to be the threshold quantity necessary to induce maximal gall bladder contraction. ${ }^{23}$ The characteristics of the test meal used in our patients seem suitable to evaluate the relation between gastric and gall bladder emptying, and the simultaneous ultrasound measurement of both events may offer important clues in assessing gall bladder function in health and disease..$^{21}{ }^{24}$ No such evaluation has been performed in patients with liver cirrhosis.

The best known method for the study of gastric emptying is scintigraphy. ${ }^{25}$ However, ultrasonography has been increasingly used for the measurement of gastric motility, including gastric emptying. Different studies, using various test meals, reported very good correlations between these techniques. ${ }^{26-28}$ The sonographic method, which is simple, reproducible, reliable, and does not necessitate exposure to radiation also allows for the simultaneous evaluation of gall bladder emptying. Indeed, gastric and gall bladder emptying have recently been studied mostly by ultrasound. ${ }^{20} 29$ This method is promising for the evaluation of the relation of gall bladder emptying to gastric emptying as a routine practice, ${ }^{24}$ and suited best the aim of our study.

We did not find an accelerated gastric emptying in liver cirrhosis patients as suggested in some experimental and clinical studies using liquid $^{81011}$ or solid-liquid meals. ${ }^{812}$ The accelerated gastric emptying in portal hypertension was first explained by altered gastric compliance due to submucosal oedema ${ }^{8}$ and later by altered antral motility. ${ }^{9}$ Hypothetically, accelerated gastric emptying might account for diminished gall bladder contraction in cirrhotics, as it results in a rapid passage of the meal through the duodenum, with lower release and earlier cessation of the effect of CCK and other peptides that contract the gall bladder.

Gastric distension is the only natural stimulus known to increase gastric emptying. ${ }^{9}$ Indeed, we found a strong inverse correlation between antral postprandial distension and the $\mathrm{AUC}_{\mathrm{ST}}$. Antral distension was not significantly different in our liver cirrhosis patients compared with controls, although it was reduced in Child C patients (in $25 \%$ of whom endoscopy revealed portal hypertensive gastropathy). The $\mathrm{AUC}_{\mathrm{ST}}$ was greater in Child $B$ and $C$ patients than in controls, indicating impaired emptying. Our results are in agreement with those of Wegener et $a l,{ }^{13}$ who found a trend towards delayed gastric emptying in alcoholic cirrhotics compared with controls, although it did not reach statistical significance. In their patients, gastric emptying time was not related to the presence of liver cirrhosis or of autonomic neuropathy. The 
autonomic neuropathy demonstrated in liver cirrhosis patients was equally common in alcohol related and non-alcohol related liver disease. ${ }^{30}$ Our results are also similar to those of Isobe et $a l,{ }^{14}$ who described delayed gastric emptying in cirrhotics. Charneau et $a l^{15}$ found delayed emptying only in cirrhotics with antral vascular ectasia. None of our cirrhotics had antral vascular ectasia, but two had portal hypertensive gastropathy.

Although delayed, gastric emptying after the test meal reached a similar magnitude in our liver cirrhosis patients at 90 minutes $(60 \%)$ as in controls.

The spontaneous gall bladder emptying in advance of the ultrasonically assessed gastric emptying is due to the cephalic phase of gall bladder contraction mediated by cholinergic pathways. Vagal stimulation initiates gall bladder contraction independently of meal composition..$^{2031-33} \mathrm{~A}$ cholinergic vago-vagal pyloro-cholecystic reflex has also been postulated to contribute to gall bladder emptying in response to antral distension..$^{34} \mathrm{We}$ found no difference between the proportion of liver cirrhosis patients and of controls in whom prompt gall bladder emptying occurred in anticipation of gastric emptying (a type I response as classified by Baxter et al). ${ }^{7}$

The three phases of gall bladder emptying after a solid-liquid meal - that is, the rapid contraction, the slow (tonic) and the refilling phases, ${ }^{673536}$ were all identified in our subjects. In cirrhotics, the rapid phase was slowed down and associated with diminished maximal emptying (Figs 2-4) compared with controls. In the controls, refilling of the gall bladder began when gastric emptying was almost completed, a pattern similar to that found in healthy volunteers by Lawson et al. ${ }^{6}$ In our liver cirrhosis patients, refilling of the gall bladder started earlier, when only $50 \%$ (cirrhosis B) or $75 \%$ (cirrhosis $A$ and $C$ ) of the gastric contents were evacuated. This interesting finding, which deserves further investigation, indicates a lack of coordination between gastric and gall bladder emptying in liver cirrhosis and suggests that humoral stimulation ceases before gastric emptying is complete, and consecutively the gall bladder refills.

Whereas the existence of larger fasting gall bladder volumes in liver cirrhosis is commonly accepted $^{3-5}$ and was also found in this study for Child C class patients, conflicting results regarding gall bladder emptying in this disease have been mentioned in different studies. We found defective gall bladder contractility in cirrhotic patients in all Child classes, independent of liver cirrhosis aetiology. This hypocontractility could be the consequence of either defective release of CCK or diminished gall bladder response to $\mathrm{CCK}$ at the receptor site.

In cirrhotic patients, the level of CCK was found to be higher than in controls, ${ }^{537}$ presumably due to impaired hepatic degradation as nearly all CCK-8 is normally metabolised on its first passage through the liver. ${ }^{38}$ Pompili et $a l^{5}$ found increased plasma CCK concentrations and normal gall bladder contraction in well compensated liver cirrhosis patients after a solid-liquid meal $(1000 \mathrm{kcal}$, $21 \%$ as fat). Davion and Capron found a normal gall bladder contraction in male patients with alcoholic cirrhosis after a Lundh test meal. ${ }^{3}$ In a previous study, we also found unimpaired gall bladder motility in cirrhotics following a liquid meal $(270 \mathrm{kcal}, 12 \mathrm{~g}$ fat). The contradictory results could be due to the different types of meals used (solid and/or liquid) and to their different fat content. ${ }^{21} 36$ Previous studies have demonstrated that solids empty from the stomach more slowly than liquids. This alone may be responsible for the in slower gall bladder emptying in response to a $\vec{\circ}$ solid meal than an equivalent liquid meal, but other factors cannot be excluded. ${ }^{21}$

As CCK concentrations are normal or increased in liver cirrhosis patients, the diminished gall bladder contractility could be $\hat{0}$ due to resistance of the gall bladder to the $\omega$ action of CCK at the receptor site in the $\vec{N}$ presence of increased plasma concentrations of 0 intestinal peptides such as VIP, somatostatin, glucagon and pancreatic polypeptide (PP), $\bar{z}$ acting as relaxing substances on the gall bladder wall. Several hormones and peptides $\frac{5}{\partial}$ known to affect gastrointestinal motor function $\vec{\bullet}$ normally undergo first pass hepatic degra- $\stackrel{0}{v}$ dation and thus their plasma concentrations are increased in liver cirrhosis. This has been demonstrated for somatostatin, VIP, and glucagon, ${ }^{39}{ }^{40}$ but no attempt has been made to correlate their plasma concentrations with gall $\mathbb{D}$ bladder emptying in this disease. Increased $\overrightarrow{\vec{D}}$ concentrations of gall bladder relaxing peptides $\frac{0}{3}$ could be responsible for early gall bladder $\bar{F}$ refilling observed in our patients with liver cirrhosis, before complete gastric emptying.

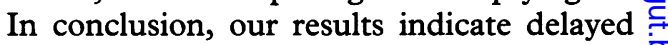
gastric emptying of a solid-liquid meal in $\frac{\sigma}{3}$ cirrhotic patients compared with controls, and impaired gall bladder emptying in these $\frac{0}{3}$ patients, which was not related to the aetiology or severity of the disease. To our knowledge, $\overrightarrow{7}$ this is the first simultaneous analysis of gastric $\frac{7}{2}$ and gall bladder emptying in liver cirrhosis patients and it indicated the lack of co- $\sigma$ ordination between the two emptying rates. $N$ Our data also support the hypothesis that diminished gall bladder contractility might $\underset{ }{0}$ contribute to increased gallstone formation in 0 liver cirrhosis.

Bolondi L, Gaiani S, Labo G Motilita della colecisti e della via biliare principale. In: Bolondi $\mathrm{L}$, Gaiani $\mathrm{S}$, Labo $\mathrm{G}, \stackrel{\mathrm{D}}{\mathrm{D}}$ eds. Ecografia funzionale ed eco-Doppler in gastroenterologia. Kurihara N, Ide $\mathbf{H}$, Omata T, Yonamine S, Mashima Y, @ Tanno $M$, et al. Evaluation of gallbladder emptying in 0 hepatobiliary scintigraphy. Radioiosotopes 1989; 38: 269-74.

3 Davion T, Capron JP. Biliary lithiasis in cirrhosis: yes, but why? Gastroenterol Clin Biol 1988; 12: 37-8.

4 Acalovschi $M$, Badea $R$, Dumitrascu DL. Gallbladder emptying in response to a fatty meal in patients with liver emptying in response to a fatty meal 7 Gastroenterol Hepato 1994; 6: 437-41.

5 Pompili M, Rapaccini GL, Caturelli E, Curro D, Montuschi P, D'Amato M, et al. Gallbladder emptying, plasma levels of estradiol and progesterone and cholecystokini secretion in liver cirrhosis. Dig Dis Sci 1995; 40: 428-34.

6 Lawson M, Everson GT, Klingensmith W, Kern F Jr Coordination of gastric and gallbladder emptying after ingestion of a regular meal. Gastroenterology 1983; 85: 866-70. 
7 Baxter JN, Grime JS, Critchley M, Shields R. Relationship between gastric emptying of solids and gallbladder emptying in normal subjects. Gut 1985; 26: 342-51.

8 Reilly JA, Forst CF, Quigley EMM, Rikkers LF. Gastric emptying of liquids and solids in the portal hypertensive rat. Dig Dis Sci 1990; 35: 781-6.

9 Jacobs DL, Quigley EMM, Rikkers LF. Gastric compliance and motility in the portal hypertensive rat. $\mathcal{F}$ Invest Surg 1992; 5: 109-14.

10 Dumitrascu DL, Barnert J, Wienbeck M. Ultrasonographic estimation of gastric emptying in liver cirrhosis [abstract]. 2nd United European Gastroenterology Week, Barcelona 1993.

11 Martinelli ALC, Meneghelli UG, Oliveira RB, Matsuda NM, Silva LR, Ejima FH. Gastric emptying in patients with portal hypertension due to schistosomiasis [abstract]. 7 Gastrointest Motil 1992; 4: 3 .

12 Balan KK, Grime SJ, Sutton R, Jones AT, Yiannakou Y, Critchley $M$, et al. Do alterations in the rate of gastric emptying contribute to the pathogenesis of portal hypertensive gastropathy [abstract]? Gut 1994; (suppl 2): S13.

13 Wegener M, Schaffstein J, Dilger U, Coene C, Wedmann B, Schmidt G. Gastrointestinal transit of solid-liquid meal in chronic alcoholics. Dig Dis Sci 1991; 36: 917-24.

14 Isobe H, Sakai H, Satoh M, Sakamoto S, Nawata H. Delayed gastric emptying in patients with liver cirrhosis. Dig Dis Sci 1994; 39: 983-7.

15 Charneau J, Petit R, Cales P, Dauver A, Boyer J. Antral motility in patients with cirrhosis with or without gastric antral vascular ectasia. Gut 1995; 37: 488-92.

16 Raws EAJ, Bolwerk CJN, Jansen PLM. Endoscopic management of variceal bleeding. In: Tytgat GNJ management of variceal bleeding. In: Tytgat GN Mulder CJJ, eds. Procedures in hepatogastroenterology.

17 Bolondi L, Bortolotti M, Santi V, Caletti T, Gaiani S, Labo G. Measurement of gastric emtpying time by real-time ultrasonography. Gastroenterology 1985; 89: 752-9.

18 Dodds WJ, Groh WJ, Darweesh RMA, Lawson TL, Kishk SMA, Kern MK. Sonographic measurement of gallbladder volume. Am $\mathcal{f}$ Roentgenol 1985; 145: 1009-12.

19 Tallarida RJ, Murray RB. Area under a curve: trapezoidal and Simpson's rules. In: Manual of pharmacologic calculations with computer programs. 2nd ed. New York: Springer Verlag, 1987: 77-81.

20 Froehlich F, Gonvers JJ, Fried M. Role of nutrient fat and cholecystokinin in regulation of gallbladder emptying in man. Dig Dis Sci 1995; 40: 529-33.

21 Fisher RS, Rock E, Malmud L. Effects of meal composition on gallbladder and gastric emptying man. Dig Dis $\mathrm{Sc}$ 1987; 32: 1337-42.

22 Perreard $\mathrm{M}$, Iconomidis $\mathrm{N}$, Bernard $\mathrm{C}$, Chayvialle $\mathrm{J}$, Gerolami A. Influence d'un regime hypolipidique sur la vidange post-prandiale de la vesicule biliaire. Gastroenterol vidange post-prandiale de la

23 Stone BG, Ansel HJ, Peterson FJ, Gebhard RL. Gallbladder emptying stimuli in obese and normal weight subjects. Hepatology 1992; 15: 795-8.

24 Takaoka M, Kubota Y, Tani K, Kin H, Ogura M, Fujimura $\mathrm{K}$, et al. Simultaneous ultrasonic monitoring of gallbladder emptying and gastric emptying after liquid test meal. Int Med 1993; 32: 758-62.
25 Malmud LS, Fisher RS, Knight LC. Scintigraphic evaluation of gastric emptying. Semin Nucl Med 1982; 12: 116-21.

26 Wedmann B, Schaffstein J, Wegener M, Schmidt G, Coenen C, Riscken D. Sonographische Erfassung der Magenentleerung. $Z$ Gastroenterol 1990; 28: 448-52.

27 Marzio L, Giacobbe A, Councitore P, Facciorusso D, Fruscianti V, Modoni S. Evaluation of the use of ultrasonography in the study of liquid gastric emptying. ultrasonography in the study of liquid
Am $\mathcal{f}$ Gastroenterol 1989; 84: 496-500.

28 Dapoigny $M$, Bonnafour J, Delasalle $P$, Abergel A, Pelissier E, Veyre A, et al. Validation d'une methode echographique de mesure de la vidange gastrique chez l'homme. Gastroenterol Clin Biol 1991; 15: 199-203.

29 Wedmann B, Schmidt G, Wegener M, Coenen C, Ricken D, Althoff J. Effects of age and gender on fatinduced gallbladder contraction and gastric emptying of a caloric liquid meal: a sonographic study. $A m \quad \mathcal{F}$ Gastroenterol 1991; 86: 1765-70.

30 Hendrickse MT, Thuluvath PI, Triger DR. Natural history of autonomic neuropathy in chronic liver disease. Lancet 1992; 339: 1462-4.

31 Hopman WPM, Jansen JBMJ, Rosenbusch G, Lamers CBHW. Cephalic stimulation of gallbladder contraction in humans: role of cholecystokinin and the cholinergic system. Digestion 1987; 38: 197-203.

32 Fullarton GM, Meek AC, Gray HW, Bessent RG. Gallbladder emptying following cholecystokinin and fatty meal in normal subjects. Hepatogastroenterology 1990; 37: 45-8.

33 Yamamura $T$, Takahashi $T$, Kusunoki $M$, Kantoh $M$, Seino Y, Utsunomiya J. Gallbladder dynamics and plasma cholecystokinin responses after meals, oral water or sham feeding in healthy subjects. Am $₹$ Med Sci 1988; 31: feeding

34 Lundgren O, Svanvik J, Jivegard L. Enteric nervous system. II. Physiology and pathophysiology of the gallbladder. Dig Dis Sci 1989; 34: 284-8.

35 Howard PJ, Murphy GM, Dowling RH. Gallbladder emptying patterns in response to a normal meal in healthy subjects and patients with gallstones: ultrasound study. Gut 1991; 32: 1406-11.

36 Marzio L, Capone F, Neri M, Mezzetti A, De Angelis C, Cuccurullo F. Gallbladder kinetics in obese patients. Effect of a regular meal and low-calorie diet. Dig Dis Sci 1988; 33: 4-9.

37 Himeno S, Tarui S, Kanayama S. Plasma cholecystokinin responses after ingestion of liquid meal and intraduodenal infusion of fat, aminoacids or hydrochloric acid in man: analysis with region specific radioimmunoassay. $\mathrm{Am} \mathcal{f}$ Gastroenterol 1983; 78: 703-8.

38 Sakamoto T, Fujimura $M$, Newman J, Zhu XG, Greeley $\mathrm{GH} \mathrm{Jr}$, Thompson JC. Comparison of hepatic elimination of different forms of cholecystokinin in dogs. $\mathcal{f}$ Clin Invest of different forms

39 Bareca T, Franceschini R, Cataldi A, Rolandi E. Plasma somatostatin response to an oral mixed test meal in cirrhotic patients. F Hepatol 1991; 12: 40-4

40 Lewis FW, Adair O, Hossack KF, Everson GT, Whitle JC, Rector WG Jr. Plasma glucagon concentration in cirrhosis is related to liver function but not to portal systemic shunting, systemic vascular resistance or urinary sodium excretion. f Lab Clin Med 1991; 117: 67-75. 